\title{
EL RELIEVE ROMANO DE COVES DE VINROMÁ (CASTELLÓN)
}

\author{
LORENZO ABAD CASAL
}

Universidad de Alicante

\begin{abstract}
Se estudia un fragmento del frontón de un pequeño naiskos con dos figuras en relive: un busto de un joven coronado, dentro de una corona, y una figura femenina anciana; el joven puede corresponder a un soldado o triunfador, y la mujer posiblemente a su madre, representada según la iconografía del invierno característica de algunos mosaicos tardorromanos. Detalles iconográficos de ambas figuras permiten proponer una datación en las últimas décadas del siglo II d. C. o a comienzos del III d. C.
\end{abstract}

A fragment of the pediment of a little naiskos with two figures in relief is studied: the bust of a young man with a crown, inside a crown, and an old female figure. The young man could be a soldier or a victor; the woman, maybe his mother, is represantated according to the iconography of the winter in late mosaics. Iconographic details of both figures allow us to propose a date about the end of the II century and begining of III century A. D.

Hace algún tiempo tuvimos conocimiento, a través de $\mathrm{E}$. Llobregat, de la existencia de un relieve romano en el pueblo castellonense de Cuevas de Vinromá. Cuando lo visitamos, el relieve se encontraba junto a la calle principal, sobre un trozo de fuste de columna y prácticamente cubierto por la vegetación que crece en el parquecillo circundante. Vecinos del lugar nos informaron de que había aparecido al derribar una casa, diez o quince años atrás, y de que no se tenía noticia de ninguna otra piedra semejante en el lugar. Entretanto, el relieve ha sido objeto de varias menciones (LLOBREGAT, $1980,106 ; A B A D, 1985,367)$ y de un artículo (ARASA, 1984, 89 ss.).

\section{DESCRIPCIÓN}

El relieve está labrado en un bloque de piedra caliza, de color grisáceo, y mide $57 \mathrm{cms}$. de largo por 51 de alto y 32 de grosor. El lado derecho presenta una fractura irregular, producto de una rotura violenta, al igual que el izquierdo, que, no obs- tante, se muestra algo más regular, excepto en su parte alta. Las caras superior e inferior tienen la superficie alisada, en tanto que la trasera queda meramente desbastada; la anterior muestra en su parte alta una moldura en resalte, en forma de filete, de sección rectangular, que debía prolongarse también por el lado izquierdo, hoy roto; la cara superior del sillar forma dos vertientes en torno a una arista central que debía corresponder al eje del monumento.

Parece evidente, pues, que nos encontramos ante la parte central del frontón de un monumento; el centro de la cara principal está ocupado por una corona formada por sendas guirnaldas de tres hojitas que, naciendo de la parte inferior, progresan hacia arriba cada una por un lado, hasta encontrarse en la parte superior, justo en la vertical del punto de arranque; éste, no obstante, se encuentra oculto por el nudo formado por una banda de tela cuyos extremos, bastante largos, cuelgan en forma de ondas por la parte inferior del sillar. Parece claro, en este caso, que se trata de la típica corona de laurel que aparece en tantos monumentos honorarios y fu- 


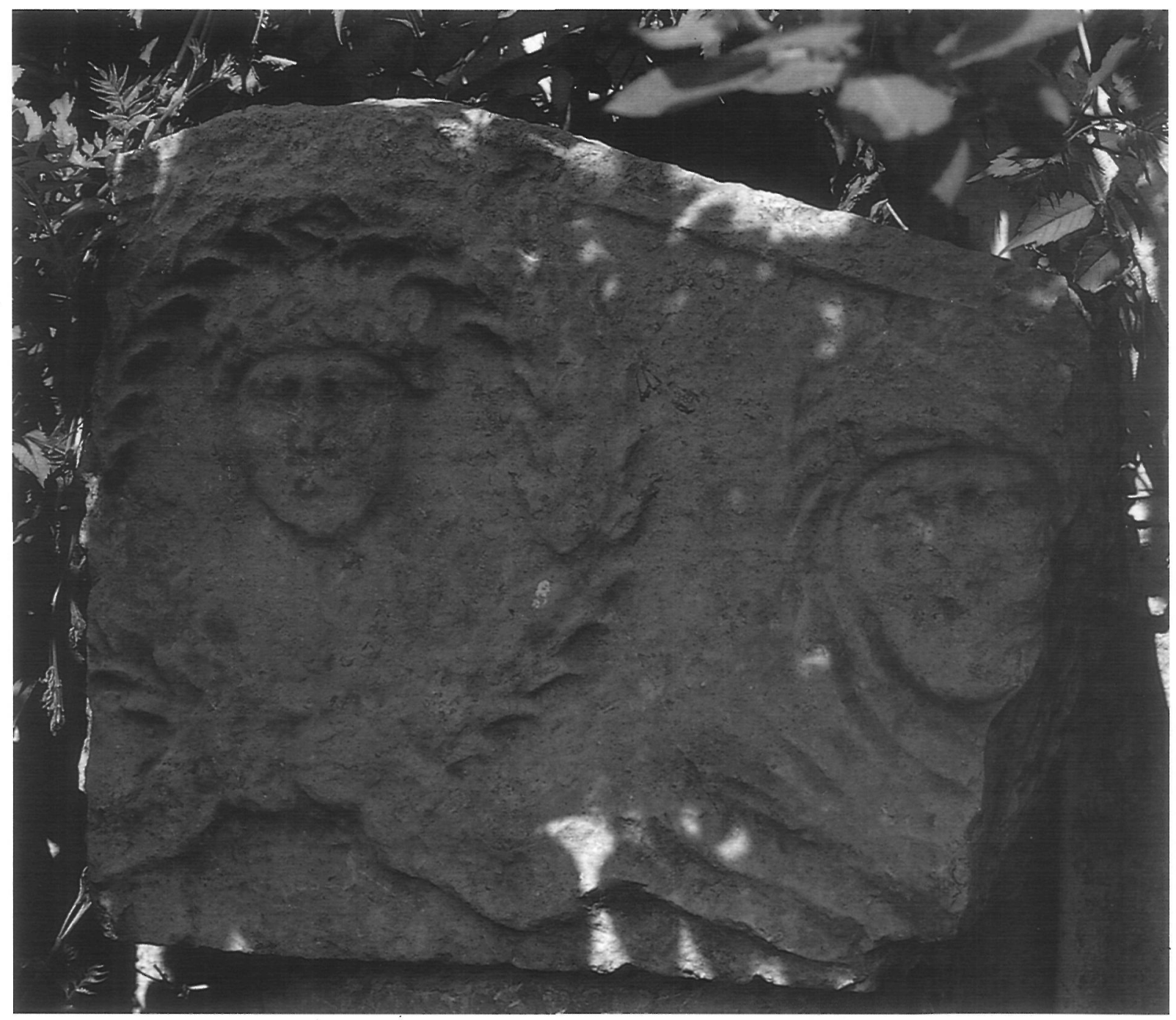

Fig. 1.-Vista general del monumento.

nerarios romanos; en su interior se encuentra representada en relieve la cabeza - y es posible que también el busto, aunque éste debía estar en bajo relieve y es difícilmente perceptible- de un personaje masculino, imberbe, de rostro redondeado, tocado con una abundante melena que llega a cubrir aproximadamente tres cuartas partes de la frente, hasta la altura de los ojos; éstos son de forma ovalada, muy abiertos, y con el globo ocular, o al menos su parte central, en resalte, en tanto los laterales se encuentran ligeramente rehundidos. Dichos rasgos son claramente perceptibles en el ojo derecho de la figura, en tanto que el izquierdo se encuentra bastante dañado, al igual que la mejilla y la parte de la nariz y la boca correspondientes a ese lado; en torno a cada uno de los ojos parece existir un engrosamiento, visible sobre todo en su parte inferior.

El pelo de la figura es, como ya hemos dicho, abundante, y forma una especie de casquete esférico que le cubre la cabeza, cayendo sobre la frente en forma de ondulaciones. Hacia la mitad de la superficie cubierta por el pelo, tal vez un poco más abajo, se aprecia una línea más o menos paralela a su contorno exterior, de la que salen, hacia los lados y a intervalos regulares, sendos resaltes que debían confluir en el centro, donde, sin embargo, sólo puede observarse una cierta protuberancia de la piedra. Parece indudable que se trata de una corona, aunque ya resulta mucho más difícil decir de qué corona se trata. En el caso de que la protuberancia 
central fuera cierta, podría corresponder a una corona de roble, la corona civica, pero no hay que olvidar que otras coronas más simples también llevaban el elemento central (cf. Corona, s. v., en $D S$. $y R E$.); lo perdido del relieve no permite mayores precisiones. El rostro no se encuentra en el centro de la corona, sino bastante desplazado hacia arriba, de tal manera que la parte superior de su pelo se encuentra en contacto con ella. Esto es claro indicio de que por debajo debía estar representado el cuerpo del personaje, que muy posiblemente estaba sólo esbozado, ya que no se conserva ningún resto.

A la izquierda de esta figura aparece una segunda, más erosionada aún que la primera, y de mayor tamaño, ya que ocupa toda la parte correspondiente del sillar; de su rostro se conserva la frente, parte de los ojos y el contorno del mentón, habiendo desaparecido todo lo que corresponde a la nariz, la boca y parte de los ojos. Presenta la cabeza cubierta con el mismo manto que le cubre los hombros, plasmado mediante profundas incisiones paralelas al contorno del rostro. Sólo muestra al descubierto aproximadamente un tercio de la frente, al igual que ocurría con la figura central, y por delante del pecho le cruza la infula izquierda de la corona central.

Aunque lo erosionado de los rostros hace dífícil un estudio minucioso, parece evidente que el personaje central es un joven, de rostro redondeado y abundante cabellera, en tanto el que lo acompaña representa a una figura ya madura y con casi toda seguridad femenina. Ello viene avalado por una protuberancia existente en el ángulo inferior derecho de la piedra, que podría corresponder a parte del pecho de la figura. Śi no se tratara del pecho, tal vez fuera parte de un nudo o de la mano izquierda, doblada ante el pecho, aunque nos inclinamos por la primera solución.

\section{TIPO DE MONUMENTO}

Parece indudable que nos encontramos ante la parte central del frontón de un monumento funerario. Cómo fuera este monumento es algo difícil de precisar, dada la escasez de los restos conservados, aunque lo más probable es que se trate de un pequeño templo, posiblemente en forma de edícula, flanqueada por dos columnas o pilastras sobre las que descansaría un arquitrabe. Según la inclinación que muestra la parte superior del sillar, el monumento debía tener una anchura de poco más de tres metros, equivalente a aproximadamente diez pies romanos. En el centro, la figura de dentro de la corona; a su izquierda, la figura femenina cubierta, y hay que suponer, jugando con los criterios de simetría propios de los frontones clásicos, que existiría otra figura semejante al otro lado de la corona. El conjunto sólo ocuparía algo más de un metro, lo que vendría a equivaler a aproximadamente un tercio de la longitud total. Los dos tercios restantes, uno a cada lado del grupo central, debieron estar constituidos por triángulos escalenos de poca altura, por lo que hay que pensar que estarían ocupados por figuras yacentes o, en cualquier caso, de pequeño tamaño. No parece probable que nos encontremos ante otros bustos, ya que éstos deberían ser demasiado pequeños. Lo único que resulta extraño en esta solución es la proporción entre la longitud y la altura del frontón, que es de 6:1, en tanto que en la inmensa mayoría de los ejemplos que hemos podido estudiar oscila entre $3: 1$ y $5,5: 1$, sin alcanzar casi nunca a la de nuestro monumento.

Edificios de este tipo son muy abundantes en todo el mundo romano. Recientemente se ha publicado uno procedente de Mérida (RODRÍGUEZ NEILA y CHAVES TRISTÁN, 1973, 295 ss.), con corona en el frontón e inscripción en el arquitrabe, que permite una datación a finales del siglo II o comienzos del III d. C.; aunque a este monumento le falta toda la parte inferior, parece claro que debía tratarse de un naiskos o templete con dos columnas o pilastras laterales, semejante al que encontramos, por ejemplo en Padua (MANSUELLI, 1963, 54, figs. 19-21), aunque en este caso, como en muchos de los que veremos a continuación, el naiskos se alza sobre un amplio basamento, que es el que presenta la inscripción. Algo parecido ocurre con el pequeño ninfeo de Sabinus Taurus en la necrópolis ostiense de Isola Sacra, un pequeño ninfeo sobre un basamento de ladrillo que sostiene la inscripción (CALZA, 1940, 317, n. ${ }^{\circ}$ 56, fig. 30), o en la de P. Vesonius, en la necrópolis de Porta di Nocera en Pompeya, también de ladrillo revestido de estuco $\mathrm{y}$, al parecer, sin decoración arquitectónica (GABELMANN, 1979, fig. 8), o en los monumentos de Sempeter, datados en el siglo II d. C. (GABELMANN, 1979). Existen también monumentos más sencillos que pueden encuadrarse en este mismo tipo, como el estudiado no hace muchos años por F. Arasa en las proximidades de Castellón de la Plana (ARASA, 1979, 147, fig. 15) o como los que aparecen representados con frecuencia en los relieves fu- 
nerarios y sarcofágicos; cf., por ejemplo, los que presiden el frente de los sarcófagos de estaciones del Museo de los Conservadores (KRANZ, 1984, n. ${ }^{\circ} 16$, lám. 15, 1) y Nueva York (ídem, n. ${ }^{\circ} 9$, lám. 15, 2), donde el podium, o bien no existe, o bien queda reducido a un simple escalón; estos monumentos, que indudablemente representan tumbas en forma de naiskos, se continuarán posteriormente, aunque de forma más simple, en la época cristiana, sobre todo en las escenas de la resurrección de Lázaro (WILPERT, 1903, láms. CXXXIX, VXXVI, CXXXII).

También podría ocurrir que el fragmento recuperado en Cuevas de Vinromá no perteneciera al frontón de un naiskos, sino que fuera en relidad el remate de una estela funeraria terminada en frontón. Estelas de este tipo son extraordinariamente abundantes en todo el mundo romano, aunque con diferentes matizaciones, según el lugar de procedencia. En unos casos es solamente el frontón el que constituye el remate de una losa rectangular con inscripción, con los retratos de los difuntos o con diversos motivos alusivos al mundo funerario, en tanto que en otras ocasiones el frontón constituye el remate de la fachada de una verdadera edícula funeraria labrada en la piedra. Entre los grupos de estelas publicados que más nos interesan, podemos destacar los del valle del Po, donde encontramos numerosos ejemplos del primer tipo (MANSUELLI, 1963, 40 ss., figs. 9 y 41) y sobre todo del segundo, aunque en algunos casos sean de dimensiones reducidas (ídem, 50 ss., figs. 23, 28, 35, 41), datadas todas ellas entre la época de Augusto y la segunda mitad del siglo II d. C. Otro grupo importante está constituido por las estelas de la región de Burdeos (BRAEMER, 1959, 99 ss.), bastante más simples, donde el frontón constituye el remate natural del nicho en el que por regla general se alberga una representación del difunto; las columnas o pilastras del naiskos originario, o bien han desaparecido, o bien han quedado reducidas a unas simples bandas en los laterales que se unen en la parte superior, sin solución de continuidad, a una banda horizontal más amplia en la que suele ir grabada la inscripción (núms. 16, 22, 25, 23, 45, 52, etc.), que en ocasiones puede ocupar también el propio frontón (núms. 4,15 ); su cronología abarca, según el autor, la época de los Antoninos y de los Severos. Un tercer grupo de estelas, en las que la idea del naiskos está plenamente asimilada, la constituyen las de la región de Aradi, en Túnez, recientemente publicadas; tienen estas estelas unos dos metros de altura y han sido datadas entre los siglos I y III d. C. y suelen mostrar un naiskos con dos columnas o pilastras laterales, por regla general acanaladas, pero en algún caso torsas, que sostienen un arquitrabe moldurado o no, un friso donde con frecuencia campean las letras $D M S$ y una cornisa con profusa decoración ornamental que encierra un frontón decorado con coronas u otras figuras simbólicas; rosetas, gorgonas, etc.; en el interior del naiskos, las representaciones de los difuntos, sobre pedestales o simplemente sobre el suelo, que constituye al mismo tiempo el remate del cuerpo inferior de las estelas, donde se encuentra la inscripción $y$, en no pocos casos, una representación figurada: un relieve alusivo al mundo o al ritual funerario o uno o varios retratos de los difuntos (FERCHIOU, 1981, 141 ss., especialmente 183 ss., núms. $1,2,4,8,11,12,20$ ).

Muy diferente es un grupo de estelas de Nórica o Panonia que, sin embargo, guarda estrechas relaciones en otros aspectos con nuestro monumento. Son estelas de uno o dos pisos sobre un basamento liso o decorado; en éste puede ir la inscripción, que también puede encontrarse en el segundo cuerpo, en tanto el tercero suele estar ocupado por el busto o los bustos de los difuntos. El segundo y el tercer piso pueden revestir forma de naiskos, bien sea mediante dos órdenes de columnas superpuestas, bien sea mediante un solo orden que acoge los dos pisos, aunque también encontramos una solución más sencilla, en forma de simple resalte de los laterales de la estela. Un frontón triangular o -más raramente- curvo, sirve de remate a las estelas y en él se acogen temas ornamentales como rosetas, aves, cabezas de medusa, escenas varias, etc., pero no coronas. Éstas se encuentra, por el contrario, en el cuerpo superior del monumento, englobando los bustos de los difuntos, que pueden ser uno solo, dos o, en los casos más complejos, hasta tres, ocupando entonces dos cuerpos. Las coronas varían considerablemente en cuanto a su grosor y modo de representación, pero casi todas ellas son verdaderas coronas, y son, en cambio, muy escasas aquéllas cuyo borde queda sin decorar (SCHOBER, 1923). Dentro de estas estelas, se da el caso particular de una serie de medallones (ídem, 144 ss.), también en forma de corona con bustos en su interior, cubiertos por un pequeño tejado a dos aguas y apoyados en un pedestal que constituía, al parecer, el remate de un determinado tipo de altar funerario (ídem, 138, fig. 159; 144 ss., figs. 164 ss.; 180 ss.). El autor data este tipo de estelas entre la época de Claudio 
y el siglo IV d. C., aunque más recientemente $\mathrm{Hu}$ deczek $(1977,440$ ss.) las ha fechado a lo largo del siglo II d. C.

Aunque la idea de representar al difunto en la estela es algo común a muchas regiones del mundo romano, e incluso para algunos de los tipos de estelas de la Panonia y la Nórica pueden apuntarse claras relaciones con el norte de Italia, el predominio de coronas como marco para el busto, y el propio emplazamiento de éstas dentro de la estela, constituye un unicum en lo que conocemos del mundo romano. Y lo mismo ocurre con los medallones bajo un pequeño tejado a dos aguas, que en su propia individualidad es algo exclusivo de estas regiones (cf. CSIR, ÖSTERREICH, II, 2, n. ${ }^{\circ}$ 106, lám. ss.). También el grupo de estelas dacias recientemente estudiadas por Teposu Marinescu y L. Bianchi (1982, 64 ss.) muestra predilección por el empleo de coronas vegetales que ocupan por regla general el frontón, pero que pueden invadir también parte del cuerpo principal, o que rematan el monumento en forma de medallón exento flanqueado por dos leones; en todos los casos, dentro del medallón suele aparecer una famila completa, compuesta en ocasiones hasta por seis miembros; todas estas expresiones artísticas se desarrollan desde el momento de la conquista hasta la segunda mitad del siglo III d. C. (BIANCHI, 1985, 18 ss.).

Si el fragmento de nuestro monumento de Coves de Vinromá correspondiera a una de las estelas del tipo que hemos examinado, debería interrumpirse antes de llegar a los extremos, tal y como lo hace, por ejemplo, en algunas estelas austríacas (CSIR, ÖST, III, 2, núms. 30 ss., lám. 10) o en la estela umbra de Asissicum (AMBROGGI, 1984, n. ${ }^{\circ}$ 40, p. 35). Pero para postular esta solución se tropieza con el inconveniente de que estas estelas suelen ser de una sola pieza, en tanto la parte inferior de nuestro monumento nos está indicando que se trata de un sillar independiente. El hecho de que la parte inferior de la cara principal carezca de la moldura que encontramos en la superior parece indicar que debía descansar sobre una piedra en la que dicha moldura ya estuviera labrada. Por todo ello creemos que nos encontramos, sin lugar a dudas, ante el frontón de un naiskos. $Y$ es este aspecto el que primero abordaremos.

\section{LOS FRONTONES}

Las edículas funerarias pueden presentar, como ya hemos indicado con anterioridad, el remate en forma de frontón o de pirámide de lados rectos o curvos. Los frontones romanos siguen en líneas generales las directrices decorativas de los griegos, aunque en aquellos edificios - funerarios o no- de pequeñas dimensiones, como el que aquí nos ocupa, el espacio disponible era muy limitado y había que buscar composiciones o motivos decorativos especialmente adecuados. Ello dependía, en gran medida, de la relación entre longitud y altura de cada uno de los frontones, ya que cuanto mayor fuera la altura, tanto más espacio disponible existiría para la inserción de la decoración. En nuestro caso, la relación es de 6,35:1, la cual es la más desfavorable para la altura de todas las que hemos podido medir, aunque se aproxima a la de algunas otras tumbas (Tumba de las Guirnaldas de Pompeya: 6:1 en la reconstrucción; tumba de C. Calventius Quietus, también en Pompeya: 6:1); en la inmensa mayoría esta relación difícilmente sobrepasa, sin embargo, los 5:1. Los frontones de estos pequeños edificios podían rellenarse de tres maneras:

3.1. Mediante la inserción de escenas figuradas de sentido histórico o mitológico. Sobre esta solución no trataremos específicamente en este trabajo, ya que por una parte ello nos obligaría a revisar todos los grandes monumentos romanos y por otra se trata de soluciones compositivas muy alejadas del monumento cuyo estudio estamos llevando a cabo; puede confrontarse, como trabajo de conjunto, el de P. Hommel (1954). En tumbas como la de Coves de Vinromá, este tipo de composiciones es bastante escaso, aunque a modo de ejemplo podríamos citar los frontones del mausoleo de Igel, en las proximidades de Tréveris (DRAGENDORFF y KRÜGER, 1924, 84, fig. 58), cuyo frontón meridional, con una relación de $2,5: 1$, permite la inclusión de la escena de Hylas y las ninfas, en forma de composición triangular. Algo parecido ocurre en el frontón occidental del mismo monumento, con una relación próxima, que alberga la escena de Marte y Rea Silvia (ídem, 85, fig. 59), aunque la composición se resuelva de otra manera. Los dos frontones restantes muestran sendos bustos del Sol y la Luna flanqueados por prótomos de sus respectivos caballos, que ayudan a cubrir, en parte, los triángulos laterales (ídem, 86-87, figs. 60-61). 
3.2. Mediante la inserción de bustos en el centro del frontón, flanquados por otros bustos o personajes menores (erotes, por ejemplo) o en posición más o menos horizontal que permitieran cubrir el espacio libre. El más conocido de todos ellos es muy posiblemente el que M. F. Squarciapino y otros autores identificaron como busto de Septiminio Severo en el fragmento de un monumento de las proximidades de la ciudad de Afrodisias, aunque tal identificación se haya aceptado no sin reticencias por parte de algunos investigadores (JUCKER, 1961, 102 ss., n. ${ }^{\circ}$ St 52 , lám. 42); el busto surge de un cáliz vegetal y la cabeza sobresale por encima del punto central del frontón, cuyos lados superiores muestran unas sencillas molduras semejantes a las de Cuevas de Vinromá, en tanto que el inferior, al igual que ocurre en éste, carece de ellas. El bloque es algo mayor que el de nuestro monumento, y debía corresponder a un frontón de unos $4,5 \mathrm{~m}$. de largo, con una relación de 4,7:1. Por desgracia, no se han conservado los bloques laterales, que nos permitirían estudiar cómo se resolvía la composición. Paralelos a este tipo de busto en el centro de un frontón los encontramos en un pequeño monumento de Alaschehir (Lidia), donde, tallados en un solo sillar, aparecen el frontón, el arquitrabe y el friso de un edificio de este tipo; por las inscripciones que cubren profusamente el frontón y el arquitrabe, sabemos que fue erigido en honor del emperador Cómmodo, a quien probablemente corresponde el busto del joven con abundante cabellera que preside el frontón, cuya relación es de 3,2:1, aproximadamente (PREMERSTEIN, 1911, 45, s., fig. 47). Una efigie de Helios preside el frontón del vestíbulo del Serapeion de Mileto, labrado a finales del siglo III d. C., sin ninguna otra figura que la acompañe, y con una relación de 7,5:1, la más alta de todas las que conocemos (KCNACKFUSS, 1924, 204 ss., figs. 215-217).

Muy interesantes son asimismo una serie de monumentos ya conocidos de antiguo, pero puestos de relieve últimamente por $\mathrm{H}$. Wrede; uno de ellos corresponde a un pequeño relieve de Turín fechado a comienzos del siglo II d. C. y muestra un frontón con el busto de un joven en su centro flanqueado a un lado por un gallo con el caduceo en su pico y al otro por un cordero; el frontón, que se encuentra perfilado por las cornisas correspondientes, forma una sola pieza con lo que debería corresponder al friso, de proporciones desmesuradas en relación con aquél, y alberga la inscripción. No sabemos si era en realidad la parte superior de un pequeño templete, o si, por el contrario, era ella misma la estela completa, aunque parece más lógico esto último (WREDE, 1981, n. 218, lám. 33). Otro relieve semejante es el de Claudia Semele, hoy en el Museo Vaticano, que muestra el busto de la difunta llevado por dos erotes que, al tiempo que la realzan, sirven para rellenar los siempre difíciles ángulos de los frontones; el monumento se data en época antoniana (WREDE, 1978, 414 ss., fig. 135). Algo más tardío es el célebre relieve de la grúa del monumento de los Haterios, datado en el año 168 d. C., en el frontón de cuyo templo aparece el busto de la difunta, velada, sin otro acompañamiento (WREDE, 1978, 415, fig. 136). Y también en este mismo siglo II d. C. debe fecharse un relieve de Peruggia en el que como elemento central del frontón de un naiskos erigido sobre una estela, con el motivo de la despedida entre sus pilares laterales, aparece un busto, posiblemente femenino, y a sus lados unos crótalos y una cista (ALTMANN, 1905, 205, fig. 162).

Otros relieves de este tipo muestran el centro del frontón ocupado por un personaje destacado, dentro de un marco circular total o parcialmente grabado en relieve. Así lo tenemos, por ejemplo, en un monumento de Corinto, donde un personaje masculino de la primera mitad del siglo II d. C., con una tenia ciñéndole el cabello, y vestido con túnica y toga, se presenta en este lugar destacado, dentro de un marco circular en relieve; el frontón original debía mostrar una relación de 4,7:1, aunque en este caso no aparece adornado con molduras y desconocemos cómo se resolvería la decoración en el resto del frontón (JOHNSON, 1931, 90, n. ${ }^{\circ} 173$ ). Un busto de Marco Aurelio ocupaba, según Deubner $(1937,73 \mathrm{ss}$.), el tímpano del gran propileo de Eleusis; en este caso, el busto del Emperador aparece asimismo dentro de un marco circular formado por dos molduras que parecen hacer referencia al marco de un escudo, con lo que nos encontraríamos ante una auténtica imago clipeata.

Otras figuras que aparecen en el centro de frontones y de marcos circulares las tenemos en el monumento de Mitrídates de Samotracia (CHAPOUTIER, 1935, 36, fig. 43; 42, fig. 56); también aquí el marco está compuesto por dos molduras de forma muy similar - aunque mucho más modestas y sin decoración- a la del escudo de Marco Aurelio, lo que hace pensar en la representación de otra imago clipeata. El frontón, que pertenece, según la reconstrucción del autor, a un templo dístilo in antis, 
tenía una relación de 6:1 y no presentaba ningún otro motivo decorativo. El templo, cuya fachada medía unos $5 \mathrm{~m}$. de largo, estaba consagrado a Mitríades Eupator, según el autor, y fue construido entre los años 102 y 101 a. C. a expensas de uno de los sacerdotes anuales. Puesto que el rostro de la imagen del clípeo ha desaparecido, y carecemos de cualquier elemento de identificación, no podemos tener seguridad de qué personaje se representaba en este lugar, aunque muy probablemente debía tratarse del mismo dios. Otro monumento de este tipo es un pequeño templete de terracota, de Tarsos, de poco más de $30 \mathrm{~cm}$. de alto, del que junto a otros fragmentos, se ha encontrado parte del frontón con un busto femenino dentro de un marco circular, cuyo peinado puede datarse en la primera mitad del siglo I d. C. (GOLDMAN, 1950, 373, n. ${ }^{\circ}$ 530, fig. 231). Motivos similares encontramos en un relieve de Dieburg, de finales del siglo II d. C., ahora en el Museo de Mainz; en él aparece Mitra delante de un templo tetrástilo en cuyo frontón se encuentra un busto humano dentro de una moldura circular que probablemente hace referencia a una divinidad del ciclo mitraico; es posible que se trate de la Luna, si pudiésemos confirmar que la moldura circular no es sino el resultado de la unión de los dos cuernos de la Luna, ya que en el relieve parecen ser bastante más anchos por abajo que por arriba (STRONG, 1934, 124, fig. XX; RÖMER, 169, n. ${ }^{\circ}$ A123, lám. 44); nos encontraríamos ante un caso parecido al del frontón de un templo de Ain-Ascia, en Siria, que muestra el busto de esta diosa como único adorno (KRECKER, 1938, 251, fig. 393, lám. 107; FLORIANI SQUARCIAPINO, 1942, 217, fig. 8).

Hasta aquí hemos examinado un conjunto de figuras que tienen en común estar en el centro de los frontones, ya sea de forma independiente, ya sea dentro de un clípeo real o transformado simplemente en una moldura circular. En muchos de los casos conocidos, las figuras se encuentran aisladas en el centro de los frontones y representan, o bien a dioses, o bien a emperadores divinizados, e incluso en algunas de las que no es visible ningún atributo divino, no parece descabellado pensar que representan a alguna divinidad, cuya identificación debía resultar bastante más fácil a sus contemporáneos que a nosotros. Es lo que ocurre, por ejemplo, con la terracota de Tarsos, que recuerda poderosamente algunas representaciones de Minerva y Diana.

Cuando todo hace pensar que se trata de una figura humana, es muy posible que nos encontremos ante algún tipo de heroización o divinización del difunto, en la línea de lo que ya en su día apuntó $\mathrm{Cu}$ mont y más recientemente ha desarrollado $\mathrm{H}$. Wrede (1978), toda vez que el frontón fue siempre un lugar sagrado del templo y el sustituir las representaciones divinas por el busto del difunto debía llevar implícitas connotaciones religiosas de algún tipo; ello es válido tanto para figuras aisladas como para las que se encuentran dentro de un clípeo o realzadas por erotes o símbolos religiosos diversos, como el busto de un joven con toga sin ningún atributo divino dentro de un medallón en una estela de CoIonia (RÖMER, 184, n. ${ }^{\circ}$ A160, lám. 48) —datado por sus editores en la segunda mitad del siglo III d. C., aunque para otros investigadores haya que retrotraerlo hasta la época constantiniana (BRÖCKER, 1975, 781, lám. VI, 3)- o las figuras frontonales de Turín o Corinto.

Con el problema de la representación de los tondoi en los frontones se encuentra íntimamente ligado el de los tondoi en general, que son extraordinariamente frecuentes en todo el mundo romano, y a los que se les han dedicado numerosos estudios y monografías, casi siempre para dirimir la ya larga polémica en torno a si el clípeo tiene en sí mismo significado religioso o si por el contrario carece de cualquier connotación de este tipo. Ya la tesis de Bolten $(1937,25$ ss.) propugnaba el sentido religioso del clípeo, que tendría como finalidad encumbrar a quien en él figuraba sobre los demás mortales, tanto por el propio carácter del monumento -reservado durante largo tiempo a emperadores y divinidades - como por la frecuente aparición de seres alados que lo sostienen. Se oponía así este autor a la tesis de Altmann (1902, 83-84), que negaba cualquier carácter religioso a estos motivos. La polémica ha rebrotado modernamente, y así, mientras F. Matz (1971, 86, 103 ss.) cree ver una verdadera «apoteosis privada» en la sustitución de las inscripciones por retratos que se produce en los sarcófagos romanos a lo largo del siglo II d. C., K. Schauenberg (1967, 54 ss.) considera que esta apoteosis o heroización se encuentra ligada no al clípeo en sí, sino a los seres que sostienen la figura de la difunta y, sobre todo, a su emplazamiento en el centro de la composición. Por su parte, H. Brandeburg $(1967,229$ ss.) cree que testimonios como el de la concesión en Atenas de un clípeo figurado a un ciudadano vivo a finales del siglo II a. C., o los numerosos testimonios de inscripciones funerarias latinas que aluden a la concesión de un clipeum argenteum 
junto al locum sepulturae, parecen exluir cualquier significado religioso y reducir el clípeo a un mero emblema decorativo.

3.3. El espacio central del frontón puede asimismo ser ocupado por una corona que sustituya al clípeo del grupo anterior; corona y roseta son, sin duda, los motivos decorativos más repetidos en los frontones de naiskoi y monumentos funerarios de pequeño tamaño, ya que, sobre todo la corona, permiten, por una parte, rellenar el espacio central y, por otra, con sus ínfulas ondeantes, alcanzar los difíciles ángulos laterales de los frontones. No es nuestra intención trazar la historia de la evolución de la corona; bástenos indicar que ya es bastante utilizada a partir de la época helenística (BLECH, 1982, ABAD CASAL, 1982, 388 ss.), y que en época romana la vemos desde muy pronto decorando tanto edificios civiles como religiosos, aras y altares funerarios. Así, un altar de la necrópolis de la Puerta de Herculano en Pompeya muestra uno de sus lados adornados con una corona cívica, de roble, aunque las ínfulas, al contrario de lo que suele ser normal, salen de la parte superior; en ello tal vez pueda verse una pervivencia de la tradición de las coronas «colgadas» helenísticas, que utiliza como motivo funerario la nueva "corona cívica» augustea, sin que ello signifique necesariamente una directa relación del difunto con el emperador o la familia imperial (KOCKEL, 1983, 95 ss., lám. 25e). Pero coronas de este tipo no decoraban sólo tumbas y altares, sino que también se encuentran en los frontones de los templos, como por ejemplo en el frontón del templo de Roma y Augusto en Ostia, decorado con una corona cívica con la leyenda $o b$ cives servatos (FLORIANI SQUARCIAPINO, 1982).

Como símbolo funerario, la corona adquiere un especial significado, y como tal la tenemos en los frontales de muchas aras (KOCKEL, 1983; ALTMANN, 1902), 184, fig. 149; 185, figs. 150 y 151 , etc.) y, sobre todo, en los frontones de no pocos altares y urnas funerarias romanas (ALTMANN, 1905 , 50, fig. 39; 54, fig. 45; 55, fig. 47; 89, fig. 74; 107 , fig. $87 ;$;09, fig. $89 ; 214$, fig. 173; GIULIANO, 1984, passim). También son frecuentes en las estelas, aunque aquí pueden establecerse algunas precisiones; son muy abundantes en el grupo de estelas de Aradis (FECHIOU, 1981, láms. 43, 44, 45, 46,56 , etc.), Nórica y Panonia (CSIR, OESTERREICH, II, 2; TEPOSU, 1982), mientras que, en cambio, raramente aparecen en las del valle del Po
(MANSUELLI, 1983) o Burdeos (BRAEMER, 1959). Además de en las estelas, las coronas son también frecuentes en los frontones de los naiskoi o templetes del tipo al que debía corresponder nuestro monumento; así la tenemos en el templo de Mérida ya citado (RODRÍGUEZ NEILA y CHAVES, 1973, 295 ss.), con una roseta en su interior, y sobre todo en los naiskoi funerarios a los que nos hemos referido con antelación, ya sea en los propios monumentos (GIULIANO, 1981, 164, n. ${ }^{\circ} 56$ ), ya sea en las representaciones que aparecen en relieves (STUART JONES, 1912, lám. 121) y sarcófagos (KRANZ, 1984 , n。 ${ }^{\circ} 19$, lám. 62 ; n. ${ }^{\circ} 16$, lám. 16, 2, etc.; HOMMEL, 1954, 108, n. ${ }^{\circ} 460$ ), constituyendo un motivo que pasará a la simbología cristiana, sobre todo en el edificio relacionado con la resurrección de Lázaro (ENGELMANN, 1973, lám. 41; WILPERT, 1903, láms. CXXXIX, 1 y 2; CXXX). En todos los ejemplos que hemos podido constatar, y que se extienden desde mediados del siglo I d. C. hasta finales del siglo $\mathrm{V} \mathrm{d}$. C., la corona se encuentra unida indefectiblemente a las infulae ondulantes que, como ya dijimos, permiten rellenar el espacio angular de los frontones.

Dentro de esta amplia serie de coronas funerarias, sin embargo, nuestro relieve nos impone una búsqueda muy claramente determinada; la de aquellas coronas en cuyo interior se encuentra representado un busto humano. Los testimonios se hacen ya menos numerosos, y comparativamente hablando son infinitamente menos abundantes que los clípeos. No puede decirse que sean exclusivos de una sola época, ya que aparecen en diferentes períodos y lugares; así, los tenemos atestiguados en unos pocos sarcófagos y estelas funerarias, en algunos frontones de templos y en algunos retratos de personajes destacados. Entre los primeros podemos citar un sarcófago de la Villa Borghese en el que dos erotes sostienen una gran corona que ocupa todo el centro del sarcófago y cuyas infulae, por detrás de los pies de los erotes, llegan hasta los mismos ángulos. La corona, de laurel y representada con grandes hojas, encierra el busto de dos personas, un hombre y una mujer, que salen de sendos cálices vegetales, y ha sido datadas por Jucker en época antonina (1961, 30, S2, lám. 7). Una composición similar encontramos en la tapa de un sarcófago del Museo de las Termas de Roma, donde dos victorias sostienen una corona de laurel con una piedra u otro objeto similar en su parte superior, con el busto del difunto en su interior; a los lados, prisioneros bárbaros 
que se relacionan con la escena de sometimiento de los bárbaros representada en el propio sarcófago. Este monumento también se ha datado en época antonina (MATZ, 1971, 110, fig. 17). En sarcófagos y otros monumentos cristianos también volverá a aparecer el tema, aunque ahora el busto de los difuntos continuará, como era norma anterior, representándose dentro de una simple moldura circular, lisa o decorada, en tanto la corona quedará reservada para albergar los símbolos religiosos y, más concretamente, el crismón (WILPERT, 1903, lám. XI, 4, CLXXXIX, CLXVIII, 4, LXXIII; TESTINI, 1966, fig. 232). En monumentos funerarios aparecen ya en estelas del tipo de libertos del centro y sur de Italia (ZANKER, 1975, fig. 34; FRANZ, 1985, n. $^{\circ} 52$, lám. 24,1 ), datadas a comienzos del siglo I d. C.; se trata no obstante, de guirnaldas muy delgadas y esquemáticas. Más adelante lo encontramos también en una estela de Niha (Siria), hoy en París, donde una corona del tipo de las ya conocidas encierra los bustos de una pareja de época de Adriano, de cuyo culto imperial era sacerdote el marido (PARLASCA, 1981, 19, lám. 20, 40). En las regiones de Noricum y Panonia es donde más abundan las representaciones de coronas con bustos en su interior, a lo largo del siglo II y quizá de los primeros años del III, aunque no ocupan el frontón sino el frente del pequeño naiskos simulado en relieve en su parte superior tal y como se ha indicado con anterioridad (HUDECZEK, 1970; SCHOBER, 1923; KRÜGER, 1970, I, 3, n. ${ }^{\circ} 340$, lám. 70). También encontramos este motivo en el friso del mausoleo de Diocleciano en Spalato, en el que una serie de erotes sostienen guirnaldas con máscaras y, entre ellas, sendas coronas con los bustos coronados de Diocleciano y su esposa Prisca (MARASOVIC, 1968, 15, figs. 87 y 89; DELBRÜCK, 1932, 124, fig. 49, lám. 61). Aparece asimismo en la decoración mural de un arcosolio de la catacumba de Trasón, encerrando un busto flanqueado por dos figuras femeninas, posible simbolización de las Musas - que, sin embargo, no lo sostienen-, y, más allá, por sendas cuadrigas vencedoras; el resto del espacio lo ocupan victorias, caballos alados $\mathrm{y}$, según algunas interpretaciones, también las estaciones (WILPERT, 1903, I, 523; CUMONT, 1942, 464, fig. 99), aunque es difícil precisar si realmente lo son. Coronas encontramos también en un frontón del Museo Nazionale romano, con un busto femenino dentro de una corona de roble, de época antonina (GIULIANO, 1982, 164, n. ${ }^{\circ} 56$ ), y en el frontón de un tem- plo funerario en Nesazio, de la primera mitad del siglo II d. C., en el que dos erotes sostienen una corona en cuyo interior aparece un busto femenino (SQUARCIAPINO, 1941-42, 220, fig. 221); WREDE, 1981, 316, n. ${ }^{\circ} 311$ ); otro frontón similar, de la misma procedencia, que Squarciapino data en época julioclaudia (loc. cit.) y Wrede en la primera mitad del siglo II d. C. (loc. cit.), muestra el busto no dentro de una corona, sino de una concha; y entre los orientales podemos traer a colación un frontón del Museo de Deva, que muestra un busto sumamente esquemático dentro de una corona sometida por dos tritones (CIVILTA, 1970, G141).

En contextos no estrictamente funerarios los tenemos representados desde muy antiguo; podemos citar un altar de Praeneste dedicado al divo Augusto (JOBST, 1984, 198, lám. 12,2), un fragmento de Benevento en el que un torso vestido con paludamentum está rodeado por dos coronas, una gruesa de laurel y otra, exterior, de roble, que ha sido identificado por Jucker como un posible retrato de Adriano (JUCKER, 1961, 91 St37, lám. 35), y un clípeo de Ankara, bordeado por una corona de laurel, sobre el que se ha discutido mucho y al que más adelante nos referiremos (BUDDE, 1965, 103 ss.). Como monumentos más tardíos pueden traerse a colación dípticos tardorromanos como los de París (VOLLBACH, 19??., 44, n. ${ }^{\circ} 41$, lám. 2), del siglo $\mathrm{V}$ d. C., en el que un cónsul aparece dentro de una gruesa corona; o en dos dípticos imperiales de Constantinopla, de comienzos del siglo VI, en los que el busto de esta ciudad es sostenido, a la antigua usan$\mathrm{za}$, por dos victorias (VOLLBACH, 1952, 48-49, n. ${ }^{\circ}$ 49-50, lám. 26).

Existen, pues, una serie de coronas con bustos figurados en su interior que abarcan muchas épocas y casi todos los aspectos de la vida romana. $\mathrm{Su}$ ordenación y estudio no ha sido emprendido aún en profundidad, ya que casi siempre se han relizado en relación con los clípeos, que son muchísimo más numerosos. Y eso que ha desde hace años se les han venido dedicando trabajos monográficos, como los de Deubner (1933) y Baus (1940), aunque en ambos casos se trata de trabajos básicamente teóricos, que poco pueden aportar al estudio concreto de un monumento determinado. Algo más tarde, F. Cumont estudió el significado concreto de las coronas en una serie de monumentos y llegó a la conclusión de que, si bien tienen su origen, junto con la palma, en los premios que se otorgaban a los atletas vencedores, pronto pasaron a significar la idea de la victoria en 
general, por lo que podrán aparecer no sólo sobre las tumbas de los gladiadores, sino también sobre las de los soldados y personajes heroizados, e incluso sobre las de gentes oscuras como símbolo de esperanza en el Más Allá. Puede utilizarse también la corona sola con el mismo significado que la corona y la palma (CUMONT, 1942, 481 ss.). Entre los diversos ejemplos que aduce Cumont, destaca especialmente un grupo de sarcófagos con representación de luchas en la palestra y la escena de coronación del atleta victorioso. El vencedor tiene la palma en la mano y al tiempo se coloca una corona sobre la cabeza. Es curioso que muchos de estos sarcófagos sean de niños, lo que obliga a pensar no en una escena de la vida del difunto, sino en una escena simbólica relativa al vencimiento de la muerte (CUMONT, 1942, 469, fig. 100, lám. XLIV, 2 y 3). Salomonson (1956, 31 ss.), al estudiar los relieves que muestran una gruesa corona con una piedra preciosa en su parte superior y un cetro sobre una silla vacía, considera que también deben tener carácter funerario y que muy posiblemente haya que ver en esta corona una representación de la que usaba el pretor en tanto que presidente de los juegos, como refiere Juvenal, por lo que estos relieves estarían relacionados con tumbas de personajes que en alguna ocasión habrían llegado a presidir juegos.

En los últimos años, el estudio de la corona como símbolo funerario ha recibido un nuevo impulso. Ya en 1965, L. Budde centró su atención en el clípeo de Ankara, cuyo marco, aunque se encuentre en relieve, trata de representar indudablemente una corona, y así lo atestiguan las pequeñas hojas incisas y, sobre todo, las bandas anudadas alrededor. Budde creyó encontrar en este busto la explicación del paso de las imagines clipeatae a los bustos dentro de coronas, ya que por una parte el borde en relieve estaría en relación con los clípeosescudos y por otra el tipo de representación de hojitas correspondería ya a las coronas propiamente dichas. Sobre la base de la corona que lleva la efigie, que corresponde a una corona de laurel, llega a la conclusión de que debe tratarse de un emperador, en cuyo caso correspondería a Trajano (BUDDE, 1965, 104 ss.). Sin embargo, la relación de derivación entre corona y clípeo que establece Budde no parece tan clara, ya que la decoración del borde de los clípeos-escudos que aduce no tiene nada que ver con las coronas; tan sólo la imago clipeata del Vaticano (BUDDE, 1965, fig. 1) podría presentar algunas semejanzas, aunque el hecho de que aquí las hojas se encuentren de forma perpendicular al eje de la corona contradice por completo el principio básico de las coronas vegetales. Esto lo advirtió ya $R$. Winkes, cuya obra (1969) contiene sustanciales reflexiones sobre el sentido de la corona como portadora de bustos humanos, independiente de la imago clipeata característica. Considera este autor (1969, 73 ss.) que el busto de Ankara no puede interpretarse como un busto dentro de corona, sino como un clípeo al borde de cuyo escudo se ha atado una guirnalda. Según él, para que una corona pueda considerarse como tal, ha de tener un punto de arranque justamente en su punto más bajo, desde donde las hojas parten en direcciones opuestas, hasta unirse nuevamente en el punto más alto, por regla general ocupado por una piedra preciosa (1969, $73,{ }^{\circ}{ }^{124}$ ). Discrepa asimismo en la consideración del clípeo de Ankara como retrato de Trajano, e incluso duda de que sea algún Emperador. Considera Winkes que la corona como portadora de un busto debió tener un significado concreto dentro del conjunto de motivos portarretratos (clípeo, concha, corona) y aduce como prueba el testimonio de la tumba de los Hatterii, donde el busto de la madre se encuentra encerrado en una concha, pero los de los hijos lo están en sendas coronas, y otro tanto ocurre con los relieves de un capitel de Tréveris, en los que Constantino aparece dentro de un clípeo y sus hijos, en cambio, dentro de coronas.

Como colofón de todo ello, puede concluirse que la corona es un motivo ornamental muy utilizado desde mediados del siglo I d. C. como símbolo de la superación de este mundo, tanto en la esfera civil como en la simbólica. Es el símbolo de los vencedores y de los soldados distinguidos, pero también de los sacerdotes y de los poetas; donde con mayor frecuencia aparece representada es en la esfera religiosa, y como tal aparece en una gran cantidad de aras, altares y templos, tanto en relieves como en la realidad. La corona concebida como marco para albergar el retrato de un personaje, en cambio, aparece sobre todo en monumentos funerarios, a partir de la época de Adriano. Parece indudable que, al igual que los clípeos y las conchas, deben hacer alusión a un tipo de heroización del difunto (1), a una cierta «apoteosis privada», como

(1) A veces, la corona puede sustituirse por una guirnalda de forma semicircular, dentro de la cual se incluye el retrato del personaje, ya sea en forma de busto, ya sea de cuerpo entero (AMBROGGI, 1984, núms. 38 y 40, págs. 35 y 55). 
han puesto de relieve en varias ocasiones Matz, Wrede y Cumont. Es muy difícil aún estudiar si la diferencia entre todos estos monumentos responde simplemente a un diverso gusto ornamental, si existe una seriación cronológica o si, por el contrario, obedece a diferencias religiosas e ideológicas más profundas. Parece claro que si bien la corona surge paralelamente al clípeo, o quizá algo antes, el busto dentro de la corona - que es posible derive del clípeo- se da con posterioridad a éste, con mucha menor abundancia, y se reserva casi exclusivamente al mundo funerario. Sería posible ver en todos estos rasgos un cierto predicamento de la corona sobre el clípeo, ya que en el mundo cristiano nos encontramos con una clara dicotomía, sin que de todas maneras pueda llegar a hablarse de una norma general: el símbolo cristiano por excelencia, el crismón, se plasmará en la mayor parte de los casos dentro de una corona, en tanto los retratos de los difuntos lo harán con preferencia en el interior de los tondos.

Por lo que respecta a los mosaicos, resulta evidente que coronas circulares formadas por haces de tres o cinco hojas aparecen en el norte de África, a partir del siglo III, haciéndose muy frecuentes a lo largo del IV; albergan en su interior motivos sumamente diversos: figuras geométricas, vegetales, animales y, también, bustos humanos. Del norte de África se extenderán a Italia y a España, donde resultarán también bastante familiar en los mosaicos tardíos (ABAD, 1982, 391 ss.).

\section{LA FIGURA PRINCIPAL}

Nuestro relieve se complica aún más por el hecho de que el personaje principal parece llevar una corona, aunque resulte prácticamente imposible identificar el tipo de corona de que se trata. Una protuberancia existente en el centro podría corresponder a la piedra central de la corona de roble, aunque tampoco hay que olvidar que muchas coronas de otro tipo también podrían llevarla (2). No se puede precisar, por tanto, de qué tipo de corona se trata, y hay que tener en cuenta, además, que en el

(2) En realidad, el estudio de la corona y de sus tipos, a partir de su representación gráfica, está aún sin hacer. Muy poco es lo que podemos añadir hoy a los trabajos ya clásicos de Haebles (sv. «Corona», $R E$, IV, 2,1636 ss.) y Saglio (sv. «Corona», $D S$, I, 1520 , ss.), pues los realizados con posterioridad son parciales. mundo romano no parece existir una rígida jerarquización en el uso de este tipo de adornos (3).

Si la corona fuera de roble, nos encontaríamos ante un atributo característico del Emperador, que, no obstante, ni la lleva siempre ni es el único en llevarla (ZANKER, 1983); podía concederse, como signo de distinción específica, al soldado que salva de la muerte a un ciudadano romano (DS, II, 1535; MAXFIELD, 1981, 70 ss.), y era también símbolo de la autoridad que preside los juegos (SALOMONSON, 1956, 33; DÍEZ, 1946, 97 ss.). Entre las demás coronas que fueron otorgadas como recompensas a los militares, y que podrían convenir a la que lleva nuestro personaje, se encuentran la corona $o b$ sidionalis y la corona aurea. Estas coronas son representadas frecuentemente en los relieves y en las estelas funerarias de sus poseedores, pero, sin embargo, son muy raras las ocasiones en que aparecen ciñendo su cabeza (estela de Marcus Caelius, en Xanten; MAXFIELD, 1981, lám. 2a); en la mayoría de las ocasiones, forman parte de conjuntos decorativos.

La corona de laurel, o al menos coronas de hojas difícilmente distinguibles de las de laurel, están mucho más extendidas; las llevan los sacerdotes y también, en algunas ocasiones, los difuntos 0 , más propiamente, los participantes en ceremonias funerarias, como puede verse, por poner un ejemplo, en la escena del banquete de la tumba de este nombre de Carmona (ABAD, 1982, 176, fig. 272).

Entre las figuras coronadas, a su vez dentro de coronas, que conocemos, figuran algunas represen-

(3) Aparentemente, el uso de coronas estaba claramente establecido entre los romanos; así, sabemos que la corona de laurel era propia del general triunfador y de sus soldados, aunque a partir de Augusto pasó a ser atributo exclusivo del Emperador; la de roble se concedía al ciudadano que salvaba a otro de la muerte, y le fue otorgada a Augusto como salvador de la patria; la de olivo era la que llevaban los jóvenes cuando marchaban al censo en los idus de junio. Pero coronas llevaban también los sacerdotes y los participantes en las ceremonias religiosas (cf., por citar un solo ejemplo, el friso del Ara Pacis, donde parece que se trata de coronas de laurel), y coronas eran otorgadas como premio en los certámenes de poesía y en los juegos circenses. Aunque lo esquemático de las representaciones figuradas, sobre todo en mosaico, no permite una total seguridad, parece que en la mayor parte de los casos se trata de la corona de laurel; sabemos que esta corona se entregó como premio en unos juegos augustales de Nápoles, pero en cambio en unos juegos capitolinos celebrados por Domiciano se entregó una corona de roble; y en otras dos ocasiones lo fue de olivo (cf. Haebler, $R E$, IV, 2, 1636, y Saglio, Ds, 1520 ss.). Para coronas militares, cf. MAXFIELD, 1981. 


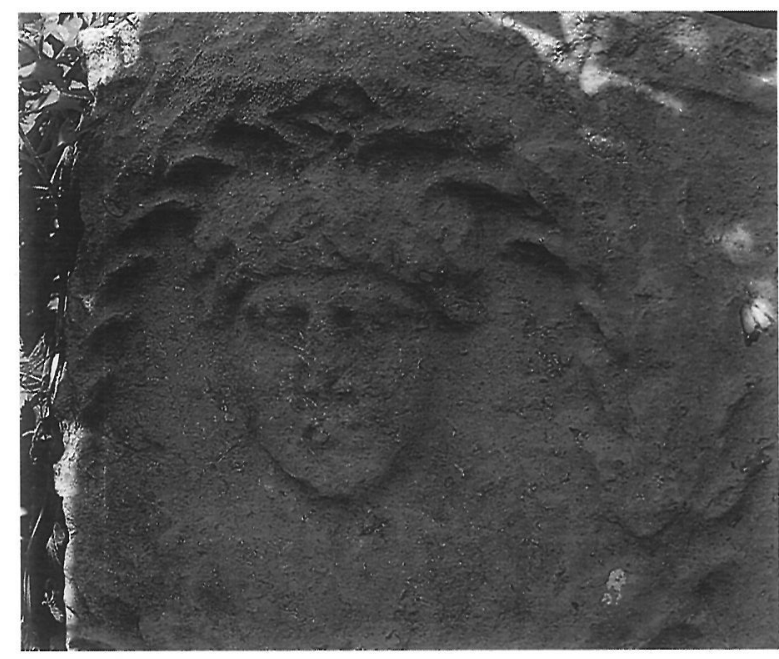

Fig. 2.-Figura masculina.

taciones de emperadores: un posible retrato de Adriano y otro de Diocleciano; en los demás, tan sólo un monumento de Ankara y otro de Corinto presentan estas características. El primero corresponde al célebre clípeo con un personaje coronado de laurel, cuya identificación como Trajano (BUD$\mathrm{DE}, 1965)$ ha puesto en duda recientemente Winkes (1969), quien cree ver en ella más bien la efigie de un ciudadano destacado cuya imagen fue colocada en un edificio público, tal vez el foro. El segundo se trata de un frontón de Corinto (JOHN$\mathrm{SON}, 1931, \mathrm{n} .^{\circ} 173$ ) en el que aparece la imago clipeata de un ciudadano anónimo con una corona que es en realidad una simple taenia.

Descartada la representación imperial, pues no parece probable que se trate de un Emperador, hemos de preguntarnos quién era este individuo. Desgraciadamente, la falta de inscripción y de cualquier elemento identificativo lo hará permanecer para siempre en el anonimato. Queda, por tanto, la posibilidad de que se trate de un sacerdote, un magistrado, un soldado o un triunfador. Como sacerdote podría ir coronado y como magistrado podría llevar la corona praetoriana de un antiguo presidente de juegos circenses, tal y como Díez y Salomonson han propuesto para relieves funerarios de otro tipo, datados en época severiana. Sin embargo, su juventud parece descartar cualquiera de estas soluciones y apunta más bien hacia una de las otras: soldado o triunfador. El único monumento que conocemos en el que aparece en el frontón el retrato del difunto tocado con una corona de laurel es una estela umbra (AMBROGGI, 1984, n. ${ }^{\circ} 40,35$ ), aunque la semejanza con nuestro relieve es bastante escasa; la figura es de cuerpo entero, aunque muy pequeña, se inscribe en una guirnalda en forma de semicírculo, y lleva un libro en una de sus manos; la suposición de la autora de que puede tratarse de un sacerdote no parece demasiado segura. En cuanto a los militares, ya hemos indicado que son muy raros los que aparecen ciñendo su propia corona.

\section{FIGURA FEMENINA}

La figura femenina que acompaña a la principal es asimismo bastante difícil de estudiar, pues carece de cualquier tipo de atributo que permita su identificación. Pero el lugar en que aparece, el frontón de un monumento funerario, nos obliga a pensar que no se trata de una figura cualquiera, sino que ha de tener un significado concreto: debe tratarse, o bien de la representación de otro difunto o de un familiar de éste, o bien de una divinidad funeraria. En el primer caso podría corresponder a un pariente del difunto principal representado dentro de la corona, que o bien mandó construir el monumento se viva, o bien se representó después de muerta. Esta solución puede apoyarse en las inscripciones que aluden a la erección de estatuas sobre arcos funerarios en zonas próximas a nuestro monumento (ABAD, 1984, 193 ss.), pero tropieza, sin embargo, con varios problemas; en primer lugar, en las estelas o en los frontones de tumbas conocidos, se suele representar al difunto dentro de una láurea, que puede ser individual o común a varios de ellos, en tanto las figuras que los acompañan son siempre simbólicas: animales, cosas, personificaciones de divinidades o fuerzas de la naturaleza. Parece raro que en el frontón de una tumba coexistan figuras de difuntos y de vivos, tal y como ocurriría en nuestro monumento si consideramos que el joven representaría al difunto, triunfante sobre la muerte, y la otra figura a la madre doliente; más bien habría que pensar que se tratara de la representación de la madre, también difunta, y que se equilibraría con la del padre u otra figura similar, situada al otro lado del frontón.

La segunda solución, la de la representación de una figura simbólica, encuentra su apoyo en que en 
muchas ocasiones la representación del difunto está acompañada por símbolos alusivos al Más Allá (delfines, etc.), y, a veces, incluso por divinidades relacionadas con el mundo funerario; así ocurre, por ejemplo, en el frontón de una tumba de Hallstatt, en cuyo centro se encuentra lo que el autor llama una imago clipeata, que más bien parece una figura dentro de una corona muy poco canónica representada hasta medio cuerpo y con una paloma en la mano; por el peinado y los collares que lleva parece una figura femenina, aunque tiene el rostro muy dañado. A su izquierda se encuentra un joven alado desnudo, que sostiene una antorcha encendida, con la llama hacia abajo, y, más hacia el exterior, un arco y un carcaj. A la derecha de la figura principal se muestra una joven semidesnuda, tendida de espaldas sobre unas rocas; tal vez se trate de una ninfa de las montañas o de Psyche en forma de ninfa; en cualquier caso, ambas son figuras alusivas al mundo funerario (ECKHAR, 1981, 56 ss., n. ${ }^{\circ}$ 74, lám. 42). También puede traerse a colación, aunque se trate de un paralelo menos exacto, una estela del grupo austríaco de Carnuntum, que en el frontal del templo muestra una corona con una mano en su interior, como es frecuente en las estelas de este origen, y, a su lado, una figura femenina de cuerpo entero, vestida con túnica y manto, que parece sostener la corona, aunque la falta de atributos y lo dañado del relieve no nos permiten precisar su identificación (KRUGER, 1970, 64, n. ${ }^{\circ} 352$, lám. 76). También entre las estelas austríacas se incluye otra que muestra en el frontón una cabeza dentro de un clípeo apoyado sobre una pequeña ara o pedestal, y sendos delfines a cada lado que cubren los triángulos de las esquinas; en su cuerpo superior, justo por debajo del frontón, encontramos una corona muy esquemática, con un águila con alas desplegadas en su interior, y cuatro bustos, uno en cada esquina, que deben representar los cuatro vientos o las cuatro estaciones, aunque también carecen de atributos (SCHOBER, 1953, 50 s., fig. 47). En otras estelas carnuntinas aparece la corona con un busto en su interior en el centro del frontón y, a sus lados, representaciones de frutos y delfines (SCHOBER, 1953, 56, fig. 55), o bien la corona, con un gallo en el interior en este caso, flanqueada por pequeñas figuritas con gorro frigio y bastón curvo que podrían identificarse con Atis (SCHOBER, 1953, 56, fig. 56).

En el caso concreto de nuestro relieve, la falta de atributos en la figura femenina no permite una

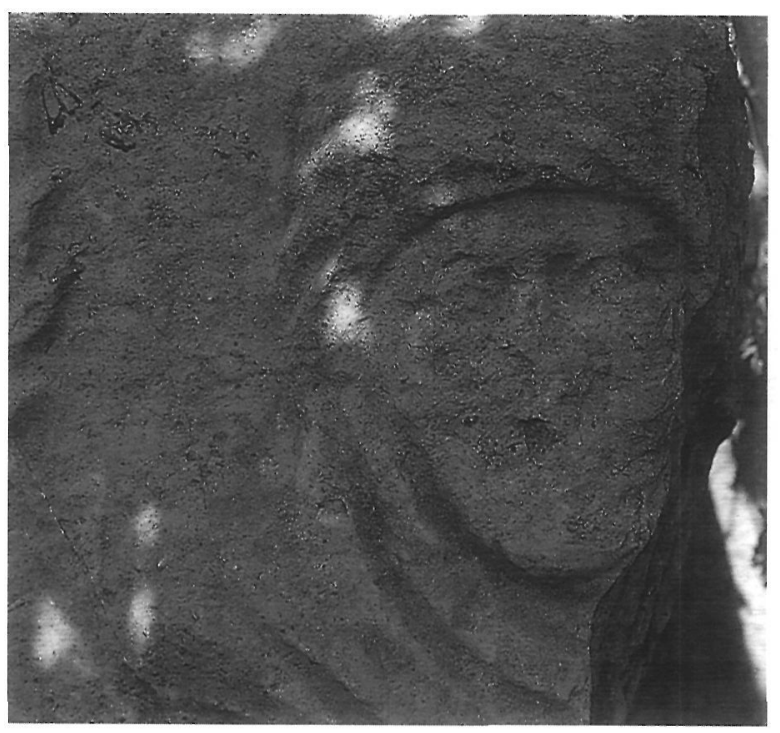

Fig. 3.-Figura femenina.

identificación clara. Hasta ahora se han propuesto dos posibles interpretaciones: la de Atis (ARASA, 1984, 91) y la de una estación (ABAD, 1985, 367; ARASA, loc. cit.). No parece probable que se trate de Atis, ya que esta divinidad se representa siempre como un joven, mientras que aquí nos encontramos con la figura de una anciana, que ni viste como Atis ni se cubre con el clásico gorro puntiagudo.

La segunda posibilidad, que en un momento determinado propusimos, se apoya básicamente en la similitud tipológica de esta figura con las representaciones del invierno en mosaicos, sobre todo norteafricanos y españoles (PARRISH, 1984: BLÁZQUEZ, 1982, n. $\left.{ }^{\circ} 15\right)$, y en la frecuente asociación de las estaciones con el mundo funerario a partir del siglo II y sobre todo del III d. C. (4), pero carece de los atributos que nos permitirían identificarla con

(4) En el mundo funerario, las estaciones comienzan a utilizarse como meras figuras alegóricas del paso del tiempo en un primer momento y adquieren poco a poco un significado escatológico de renovación permanente de la naturaleza y de la vida (CUMONT, 1942, 489; HANFMANN, 1951, 11, ss., especialmente 185 ss. y 230 ss.), adquiriendo creciente importancia en las representaciones funerarias a partir del siglo II d. C. y, sobre todo, a partir del III (HANFMANN, 1951, 232 ss.). Donde más intensa es esta relación entre estaciones y mundo funerario es en los sarcófagos, y el reciente estudio de P. Kranz (1984, núm. 49, lám. 24) es un buen ejemplo de ello; son numerosísimos los 
certeza como tal y no responde al tipo característico de estaciones funerarias, representadas casi siempre por erotes masculinos (5); si bien algunas representaciones en mosaico aparecen asimismo desprovistas de atributo, no creemos que la relación entre nuestra figura y el invierno de los mosaicos pueda ir más allá de lo meramente formal.

Nos parece, más bien, que nuestra figura debe estar en la tradición de las madres que, con el manto sobre la cabeza en señal de luto y de dolor, aparecen sobre todo en las estelas itálicas, tanto en las de libertos tardorrepublicanos y de comienzos del imperio (ZANKER, 1975; FRENZ, 1985), como en las más tardías, datadas entre la época de Augusto y finales del siglo II d. C. y estudiadas por Mansuelli (1963, 40 ss.); mucho más rara es esta representación, sin embargo, en los demás grupos de estelas

sarcófagos en los que aparecen asociadas al clípeo central; la más antigua se documenta a comienzos del s. II d. C., aunque el clípeo no lleva áun el retrato del difunto, sino sólo una inscripción funeraria (KRANZ, 1984, núm. 49, lám. 24). Años más tarde, ya a fines del siglo II, encontramos monumentos en los que las propias estaciones llevarán el clípeo (no la corona) con el correspondiente retrato. Son los sarcófagos núm. 31 (ídem, lám. 22, 1), datado en los años 180-190, y 13 (lám. 24, 4), de los últimos años del siglo II d. C. En estos sarcófagos, erotes masculinos cubiertos sólo con una piel anudada sobre un hombro, excepto el invierno, que lleva además una túnica de manga larga y gorro frigio - caso del sarcófago de Buffalo (núm. 31) - o la cabeza cubierta por el propio manto - caso del de Pisa (núm. 43)-, simbolizan las diversas estaciones y sostienen los respectivos clípeos, en un tipo sarcofágico que perdurará hasta época tetrárquica (núms. 55, lám. 40,1;59, lám. 40,3; 47, lám. 53, 2) y constantiniana (núm. 34 , lám. 39, 3; 47). Estaciones que en lugar de clípeos lleven corona son mucho menos frecuentes, y las encontramos tan sólo en sarcófagos del Palacio Cristiniani de Roma y del Museum of Fine Arts de Boston (núm. 50, lám. 34, 1 y 2; 36,2 ), datados entre el 250 y $260 \mathrm{~d}$. C. y correspondientes a la serie de erotes masculinos, cubiertos con la clámide terciada sobre un hombro. Dentro de esta serie, el invierno suele ir desnudo como los demás, aunque a veces lleva un chitón corto, pantalones y botines, y, en ocasiones, un manto en torno a la cabeza y los hombros, como en un sarcófago columnado antoniniano de Zurich (núm. 26, lám. 7,2) y en otro de época contantiniana (núm. 133, lám., 59, 2).

La asociación de las estaciones con naiskoi funerarios como el monumento de Coves de Vinromá está también atestiguada en un sarcófago del Palacio de los Conservadores de Roma (KRANZ, núm. 16, lám. 15, 1), cuyo centro está ocupado por el frente de un templo; en el frontón campea una corona, y en sus puertas, entreabiertas, figuran las representaciones de las cuatro estaciones, en forma de erotes, en relación con las cuatro estaciones características, en forma de genios, en los intercolumnios contiguos (WREDE 1978, lám: 139, 3).

(5) Estaciones femeninas las encontramos raramente en el frente de los sarcófagos, pero las tenemos, por ejemplo, representadas a manera de estatuas, entre las pilastras que decoran que hemos tenido ocasión de examinar, por lo que parece característica de Italia en época altoimperial. Sin embargo, la figura velada que aparece en estas representaciones es muy diferente tipológicamente de la de nuestro relieve: muestra el cuello descubierto y el manto apenas llega a cubrir la parte superior de la frente. Nuestra figura se encuentra mucho más próxima a las representaciones del invierno de algunos mosaicos que a sus paralelos escultóricos, a no ser en algunas personificaciones del invierno en unos pocos sarcófagos (cf. nota 5). Si esta relación es meramente tipológica o si por el contrario responde a una asociación iconográfica más profunda, es algo que hoy por hoy no podemos precisar.

Resulta evidente que las dos figuras de nuestro relieve están estrechamente relacionadas, aunque ya sea más difícil precisar si el tipo de relación que las

el frente de un sarcófago de Génova (KRANZ, 1984, núm. 7, lám. 18, 1); la Hora del invierno, en este caso, lleva también un manto que le cubre la cabeza, y lo mismo ocurre en el sarcófago columnado de Ampurias, datado por García y Bellido en el siglo IV (1984, núm. 272) y por Kranz en el III avanzado (1984, núm. 573, lám. 121, 1), donde la representación del invierno aparece también envuelta en un manto que le cubre la cabeza y el cuello, en una forma muy similar a la del relieve de Vinromá. Más abundantes son, en cambio, las Horas femeninas que simbolizan estaciones en las tapas de los sarcófagos, para las que Kranz propone una datación entre mediados del siglo II (núms. 374, lám. 96, 2; 372, lám. 96, 3; 411, lám. 98, 5; 360, lám. 99, 7; 371, lám. 99, 8) y el año 320, aproximadamente (núm. 363, lám. 103, 4). La inmensa mayoría procede, sin embargo, de época antonina (núm. 343, lám. 96, 4; 373, lám. 98, 6), siendo pocos los que se adentran en el siglo III (núm. 400, lám. 195, de hacia 200; 399, lám. 96, 1, de hacia 240; 398, lám. 98, 2, de hacia 260), y muy escasos los que llegan al IV (núm. 363, lám. 103, 4). Esta disminución progresiva se debe a la sustitución de la Hora femenina por el erote masculino, en directa relación con el predominio de erotes y genios masculinos que ya habíamos observado en la cara principal del sarcófago.

El tipo de Hora femenina en estas tapas es el de cuatro mujeres - recostadas para adaptarse a la forma alargada de la tapa del sarcófago-, con sus correspondientes atributos y dispuestas de manera afrontada dos a dos; entre ellas aparecen erotes, también con atributos estacionales, que, a la larga, acabarán ocupando su lugar. El invierno suele ocupar uno de los ángulos, por regla general el izquierdo, y se encuentra vestido con una túnica de manga corta y un manto que le cubre la cabeza; también los erotes que le corresponden suelen estar vestidos, y en alguna ocasión presentan incluso la cabeza cubierta (KRANZ, 198, núm. 400, lám. 104, 3). El invierno de la tapa del sarcófago núm. 367 (lám. 103, 2), de hacia el 320, tiene el manto que cubre la cabeza cruzado por delante del pecho, en una disposición muy semejante a la de nuestra figura de Coves de Vinromá, en tanto que en las demás suele quedar el cuello al desnudo. Posteriormente, estas figuras serán sustituidas por erotes, entre los cuales el del invierno se nos seguirá presentando como el más abrigado, aunque, a diferencia de lo que ocurría antes, ahora no será raro ver también vestidos a los demás (láms. 106 y ss.). 
une es familiar o simbólico. En el primer caso, que parece el más probable, nos encontraríamos ante una madre doliente y su hijo triunfante, heroizado. La composición debería completarse con una tercera figura, que equilibrase la de la madre, y que posiblemente se tratara del padre. Este esquema puede ponerse en relación con numerosos relieves en los que aparece una composición familiar, a base de padre, madre e hijo pequeño, sobre todo en las estelas itálicas de libertos a las que ya nos hemos referido (ZANKER, 1975, figs. 24 y 29), y también en las estelas dácicas (MARINESCU, 1982, S157, M25, M19); sin embargo, ni en uno ni en otro caso pueden extraerse conclusiones que vayan más allá de una simple relación formal: en el caso de las estelas itálicas, las figuras de los hijos aparecen siempre entre los padres, a una altura ligeramente más elevada, pero como representación de auténticos bustos escultóricos; parece que esta tradición se mantuvo en algunos casos a lo largo de siglos posteriores; así podemos ver un relieve de un matrimonio, datado hacia $170 \mathrm{~d}$. C., con el busto del hijo entre las cabezas de los padres, procedentes del sur de Italia (FRENZ, 1985, n. ${ }^{\circ}$ 32, lám. 15, 1), y otro relieve de Burdeos, datado en época severiana, de composición parecida, aunque mucho más esquemática (BRAEMER, 1959, n. ${ }^{\circ} 42$, lám. 12). En las estelas dácicas, por el contrario, aparece entre los padres y es de menor altura que éstos, pero en ningún caso encontramos la figura del hijo tan destacada como en nuestro relieve, dentro de un marco específico, y tampoco aparece en frontones, sino siempre dentro del cuerpo principal de la estela. No obstante, a diferencia de lo que ocurre en casi todos estos monumentos, la figura de nuestro relieve no corresponde a un niño de corta edad, sino a un joven ya plenamente desarrollado.

Si considerásemos a la figura femenina como una estación, el simbolismo funerario se acrecentaría, ya que la relación con el personaje central trascendería la puramente familiar para pasar a la esfera de lo simbólico. Para su correcta interpretación habría que identificar previamente al personaje central y determinar a qué responde la corona que lleva. Sería posible que se tratase de la representación de un auriga vencedor asociado a la de una estación, ya que el primero suele representarse a partir de fines del siglo II d. C. con una corona que recibe como premio, y se encuentra en estrecha relación con las estaciones, dentro del simbolismo cósmico que parece característico del circo romano (LYLE,
1984,826 ss.); en algunos mosaicos aparecen asociados el auriga vencedor con las estaciones, como ocurre en los de Rudtow, de mediados del siglo IV (LING, 1983, 18 ss.) y Ste. Colombe les Vienne, de finales del II o comienzos del III (HUMPHREY, 1986, 375 ss.), pero tampoco conocemos paralelo alguno claro para la asociación que encontraríamos, en este caso, en nuestro monumento: un auriga coronado, dentro de una corona, y flanqueado por estaciones.

\section{ICONOGRAFÍA}

Un importante elemento lo constituye el peinado de la figura masculina que encontramos en el centro del frontón y que ya hemos descrito al principio del trabajo: cabello abundante en forma de casquete, que cubre casi toda la frente y llega hasta algo más abajo de la línea del ojo. Es un tipo de peinado que se da ya en la época de Trajano, aunque con melena menos abundante y el pelo de las sienes mucho más corto, de manera que casi nunca llega a cubrir las orejas; es el peinado que vemos, por ejemplo, en un busto de Roma (HATTO GROS, 1940, 124, n. $^{\circ} 4$, láms. 6 b y 7 ) o en cualquiera de los más conocidos retratos de Florencia (ídem, 126, n. ${ }^{\circ} 15$, lám. 12) o de Ostia (ídem, 132, n. ${ }^{\circ}$ 74, láms. 3335 ), aunque aquí con la frente algo más despejada. Un peinado parecido, con melena algo más creci$\mathrm{da}$, es relativamente frecuente entre los emperadores antoninos; así lo vemos, por ejemplo, en Adriano (retratos de Roma, Florencia y Sevilla; WEGNER, 1939, 141, lám. 3; 96, lám. 4; 113, lám. 19a), Antonino Pío (WEGNER, 1939, 141, lám. 3) y Marco Aurelio (WEGNER, 1939, 203, lám. 16b, 171, lám. 19), pero sobre todo en los de Lucio Vero, cuya melena le cubre buena parte de la frente, como ocurre, por ejemplo, en los retratos del Vaticano y Atenas (WEGNER, 1939, 244, lám. 40; 226, lám. 45). Más adelante, la frente volverá a despejarse, excepto en algunos retratos de Caracalla joven, como los del Museo de las Termas, Tolouse y Copenhague (WIGGERS, 1971, 79, lám. 1, 87, lám. 3b, 65, lám. 3d). Nuestra figura carece de barbilla, como es normal en los jóvenes de la época de los Antoninos y puede verse en los retratos de Lucio Vero de Olimpia (WEGNER, 1936, 237, lám. 39); Commodo de los Musos Capitolino y de las Termas (WEGNER, 1936, 264, s., lám. 48, 49a, 50) y también en los ya citados del joven Caracalla. Este tipo de peinado no 
volveremos a encontrarlo ya en la plástica romana hasta la época de Constantino, momento en que volverá a imponerse uno bastante parecido, sobre todo al de Trajano, tal vez dentro del marco del «renacimiento» artístico que tiende a buscar elementos de inspiración en los momentos de esplendor de los primeros siglos del Imperio (DELBRÜCK, 1933, 36 ss.); será éste uno de los tipos que con más frecuencia lucirán el emperador y sus hijos, como vemos, por ejemplo, en la cabeza de mármol de Constancio II de la Villa Borghese de Roma (DELBRÜCK, 1933, lám. 50), de aspecto muy parecido a los trajaneos, aun cuando la parte superior del cabello tenga un tratamiento bastante distinto, o en el propio Coloso de Barletta (ídem, 219 ss., lám. 116 ss.), y sobre todo, en numerosísimos relieves, tanto en piedra como en marfil y otros materiales; zócalo del obelisco de Constantinopla (ídem, 186 ss., láms. 85 y 87-88), dípticos consulares de Probianus (VOL$\mathrm{BACH}, 1952, \mathrm{n}^{\circ}$ 62, lám. 34) y Estilicón (ídem, n. ${ }^{\circ}$ 63, lám. 22), y otros varios de París (ídem, $\mathrm{n} .^{\circ} 41$, lám. 22; n. ${ }^{\circ} 58$, lám. 31) y Constantinopla (núms. 8 ss.).

A uno de estos períodos debe adscribirse el peinado de nuestra figura central, $y$, aunque lo dañado del mismo impide profundizar en los criterios estilísticos, sus características aún visibles parecen apuntar hacia un momento del fin de los Antoninos o de principios de los Severos, en la línea de los jóvenes príncipes herederos; no es de extrañar que un joven como el representado en nuestra estela no lleve tampoco barba y que sus orejas queden cubiertas por la abundante cabellera.

Otro tanto ocurre con la figura de la madre, en la que han desaparecido todos los rasgos faciales que permitirían un estudio estilístico; no obstante, el único criterio que podemos aplicar, el iconográfico, nos indica que el modo de llevar el manto está muy lejos de las representaciones altoimperiales y recuerda mucho, en cambio, las representaciones musivarias del invierno, existentes ya desde mediados del siglo II a. C.

\section{CONCLUSIONES}

Se trata de un frontón de un templete funerario en el que se representa a un joven heroizado y a una figura femenina, que bien puede ser su madre; en este caso debería flanquearlo al otro lado una figura masculina. El joven lleva una corona, como dis- tintivo de su rango o función, y la figura de la madre recuerda poderosamente la de la representación del invierno en algunos mosaicos tardorromanos, hasta tal punto que pensamos que el escultor se ha inspirado para sus modelos en los repertorios $\mathrm{mu}$ sivarios de procedencia norteafricana que deberian estar en boga en la Península Ibérica en la época a la que creemos que corresponde el monumento.

En cuanto a la cronología, los distintos elementos permiten proponer una fecha antonina avanza$\mathrm{da}$, o severiana inicial, que puede corresponder a los últimos decenios del siglo II o a los primeros del III. En este período se datan, como hemos visto, la mayoría de los templetes funerarios cuyo frontón está presidido por una corona con un busto en su interior; ha aparecido ya la figura del invierno en los pavimentos africanos y europeos y existe, entre Lucio Vero y Caracalla, un tipo de peinado bastante parecido al que lleva la figura central. Los materiales arqueológicos del entorno indican una cronología del siglo II y primera mitad del III d. C., y tampoco habría que olvidar - aceptando la posibilidad de que el joven representado correspondiera a un militar - que es precisamente en esta época cuando dejan de otorgarse, y por consiguiente de representarse, los dona militaria, entre los que habría que incluir la corona que porta (MAXFIELD, 1981, 248 ss.).

Nos encontramos, pues, ante un monumento provincial, de no demasiada calidad artística, pero hecho en un momento en que aún se domina la técnica de la escultura clásica, antes de la disolución formal del Bajo Imperio. Puede constatarse, por una parte, la persistencia de algunos esquemas clásicos (edificio funerario en forma de templete, corona en el frontón, etc.), que pervivirán durante buena parte del siglo III, y, por otra, el anuncio de los primeros motivos tardorromanos; madre doliente que adopta la iconografía de una estación y corona empleada como marco para albergar un retrato, principalmente.

\section{ADDENDA}

1. La comparación del relieve de Coves de Vinromá con estelas y relieves similares de la Península Ibérica queda reservada para un artículo posterior.

2. Redactado ya este trabajo, hemos tenido conocimiento de varios monumentos funerarios que de una u otra forma presentan a las estaciones en 
relación con un motivo principal. En primer lugar, un relieve de Gröbming (Austria), del siglo II avanzado o del III d. C. y claramente funerario, en el que un medallón con el busto de un viejo barbado, que representa al invierno, aparece como único superviviente de un grupo de cuatro estaciones que flanqueaban un tondo central con la representación de un difunto heroizado, posiblemente en camino hacia la luna (DÍEZ, E. "Mondfahrt der Seele», Ojh, 42, 1955, 74 ss.). En otro relieve funerario de Globasnitz, también en Austria, y datado en el siglo II d. C., dos bustos femeninos, que representan al invierno, y probablemente también al otoño, flanquean un medallón central con la representación de una ménade desnuda, con tirso y címbalo; deben faltar otros dos medallones simétricos con la representación de la primavera y el verano. La figura del invierno está bastante próxima tipológica y estilísticamente de la de Coves de Vinromá (PICCOTTINI, G. CSIR, IV, 2, 1984, n. ${ }^{\circ} 312$ ).

Por otra parte, en la decoración pintada de un columbario de la Vía Portuense de Roma, encontramos hornacinas coronadas por frontones, en cuyo centro aparecen retratos de jóvenes dentro de medallones, en relación con las estaciones que decoran la bóveda de la tumba (BORDA, M. Pittura romana, Milano, 1958, 102, tav. color 7). Asimismo, en varios relieves funerarios conocidos por dibujos antiguos, alguno de los cuales se conserva aún en el Museo Británico, aparecen difuntas heroizadas dentro de edículas coronadas por arcos cuyos salmeres y claves estaban decoradas con bustos dentro de tondos en algunos de los cuales hay que ver la representación de estaciones (WREDE, 1978, 412, fig. 133).

Todo ello permite confirmar una fuerte relación de las estaciones con la iconografía funeraria, en la línea apuntada más arriba, aunque el hecho de que en todos los monumentos reseñados las estaciones aparezcan siempre en medallones $o$, en cualquier caso, aisladas o independientes del motivo central, nos obliga a reafirmarnos en las conclusiones que anteriormente expusimos.

\section{BIBLIOGRAFÍA}

ABAD CASAL, L. 1982: Pintura romana en España. AlicanteSevilla.

- 1984: «Arcos romanos en el País Valenciano: los testimonios epigráficos», Lucentum, II.

- 1985: «Arqueología romana del País Valenciano: panorama y perspectivas». Arqueología del País Valenciano: panorama y perspectivas. Alicante.
ALFOELDY, A. 1970: Die monarchische Repräsentation in römischen Kaiserreich. Darmstadt.

ALTMANN, W. 1902: Architektur und Ornamentik des antiken Sarkophage. Berlín.

- 1905: Römische Grabaltäre der Kaiserzeit. Berlín.

ARASA I GIL, F. 1979: «Arqueología del terme municipal de Castelló de la Plana». Cuadernos de Prehistoria y Arqueología Castellonense, 6.

- 1984: «El relleu hispano-romà d'Els Tossalets (Les Coves de Vinromá)», Boletín del Centro de Estudios del Maestrazgo, 6.

BAUS, K. 1940: Der Kranz in Antike und Christentum. Bonn. BIANCHI, L. 1985: Le stele funeraire della Dacia. Roma.

BLÁZQUEZ, J. M. 1982: Corpus de mosaicos romanos de España, IV. Madrid.

BLECH, M. 1982: Studien zum Kranz bei den Griechen. Berlín.

BOLTEN, J. 1937: Die imago clipeata. Ein Beitrag zur Portrait und Typengeschichte. Padeborn.

BRAEMER, F. 1959: Les stèles funéraires de Bordeaux. París.

BRÄCKER, J. 1975: «Das römische Köln, I». Aufstieg und Niedergang der römischen Welt, II, 4.

BRANDENBURG, H. 1967: «Meerwesensarkophage und Clipeusmotiv. Beiträge zur Interpretation römischer Sarkophagre!iefs», Römische Mitteilungen, 82.

BUDDE, L. 1965: «Imago clipeata des Kaisers Trajan in Ankara», Antike Plastik, IV.

CALZA, G. 1940: La necropoli romana de Isola Sacra. Roma.

CIVILTA, 1970: Civiltà romana in Romania. Roma.

CSIR: Corpus signorum imperii romani.

CUMONT, F. 1942: Recherches sur le symbolisme funéraire des romains. París.

CHAPOUTIER, F. 1935: Le sanctuaire des dieux de Samothrace, Exploration archéologique de Délos, XVI. Paris.

DAREMBERG, 1877: DAREMBERG, SAGLIO ET POTIERS, Dictionnaire des antiquités grecques et romaines. París.

DELBRÜCK, R. 1932: Antike Porphyrwerke. Berlín und Leipzig.

- 1933: Spätantike Kaiserporträts. Von Constantinus Magnus bis zum Ende des Westreichs. Berlín.

DEUBNER, L. 1933: «Die Bedeutung des Kranzen in klassischen Altertum», Archiv für Religionswissenschaft, 30.

DEUBNER, O. 1939: «Zu den grossen Propyläen von Eleusis», Athenaische Mitteilungen, 62.

DÍEZ, E. 1946: «Die Sella curulis auf provinzialrömischen Reliefsteinen des Steiermark», Oesterreische Jahreshefte.

DRAGGENDORFF, H., y KRÜGER, E. 1924: Das Grabmal von Igel. Trier.

ECKHART, L. 1981: CSIR. Österreich, III, 3.

ENGELMANN, J. 1973: Untersuchungen zur Sepulkralsymbolik des späteren römischer Kaiserzeit. Münster.

FERCHIOU, N. 1981: «Grandes stéles à décor architectural de la région de Bou Aradas (Aradi) en Tunisie» Römische Mitteilungen, 88.

FLORIANI SQUARCIAPINO, M. 1982: «Corona civica e clipeus virtutis da Ostia», Miscellanea Archaeologica Tobias Dohrn dedicata. Roma.

GABELMANN, H. 1979: Römische Grabbauten der frühen Kaiserzeit. Sttutgart.

GARCÍA Y BELLIDO, A. 1948: Esculturas romanas de España y Portugal. Madrid.

GLAUCKER, L. 1902: Mémoires de la Societè des Antiquaires de France.

- 1910: Inventaire des mosaiques d'Afrique, II.

GIULIANO, A. 1981: Museo Nazionale Romano. Le sculture, I, 2. Roma.

- 1982: Museo Nazionale Romano. Le sculture, I, 3. Roma. 
- 1984: Museo Nazionale Romano. Le sculture, I, 7. Roma.

GOLDMANN, H. (ed.). 1950: Excavations at Gözlu Küle, Tarsus, I-II. Princeton.

GRABAR, A. 1968: Christian Iconography. Princeton.

HANFMANN, G. 1951: The Season Sarkophags in Dumbarton Oaks. Cambridge (Mass.).

HATTO GROS, W. 1940: Bildnisse Trajans. Berlín.

HOMMEL, P. 1954: Studien zu den Figurengiebeln der Kaiserzeit. Berlín.

HUDECZECK, E. 1977; «Flavia Solva». Aufstieg und Niedergang der römischen Welt, II, 6 .

HUMPHREY, J. 1966; Roman Circuses. London.

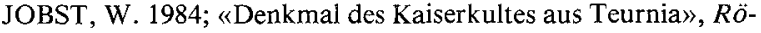
misches Oesterreich, 11-12.

JOHNSON, F. P. 1931: Corinth, IX, Sculpture. Cambridge.

- JONHSON, F. P. 1931: Corinth, IX, Sculpture. Cambridge (Mass.).

JUCKER, J. 1961: Das Bildnis im Blätterkelch. Lausanne.

KNACHFUSS, H. 1924: Der Südmarkt und die benachbarten Bauanlagen. Berlín.

KOCKEL, V. 1983: Die Grabbauten vor dem Herkulaner Tor in Pompeji. Mainz.

KRANZ, P. 1984: Jahreszeiten Sarkophage. Berlín.

KRECKER, D. y ZSCHIETZSCHMANN, 1938: Römische Templen in Syrien. Berlín.

KRÜGER, M. L. 1970: CSIR, Österreich, I, 3. Wien.

LEVI, D. 1948: Antioch Mosaics Pavements. Princeton.

LING, R. 1983: "The Seasons in Romano-British Mosaic Pavements» Britannia, XIV.

LYLE, E. B. 1984: «The Circus as Cosmos». Latomus, 43.

LLOBREGAT, E. 1980: Nuestra Historia, II. Valencia.

MANSUELLI, G. 1963: «Les monuments commémoratifs romains de la Vallée du Po», Monuments et Mémoires E. Piot, 53.

MARASOVIC, J., y T. 1968: Der Palast des Diokletian. Wien und Müchen.

MATZ, F. 1971: «Stufen der Sepulkralsymbolik in der Kaiserzeit». Archäologischer Anzeiger, 86.

MAXFIELD, V. A. 1981: The Military Decorations of the Roman Army. Berkeley.

PARLASCA, K. 1981: Syrische Grabreliefs hellenistischer und römischer Zeit. Mainz.

PARRISH, D. 1984: Seasons Mosaics of Roman North Africa. Roma.
PREMERSTEIN, A. V., y KEIL, J. 1911: «Marmorgiebel mit Commodus-Büste», Oesterreiche Jahreshefte, Beiblatt, 14, 1911.

RE: Real Enzyklopädie des klassischen Altertumswissenschaft.

RODRIGUEZ NEILA, J. F., y CHAVES TRISTÁN, F. 1973: «Un monumento funerario procedente de Emérita», $\mathrm{Ha}$ bis, 4.

RÖMER, 1967: Römer am Rhein. Köln.

SALOMONSON, J. 1956: Chair, Sceptre and Wreath. Gröningen.

SCHAUENBERG, K. 1967: «Perückenträgerin im Blätterkelch», Städel-Jahrbuch, 1 .

SCHOBER, A. 1923: Die römischen Grabsteine von Noricum und Pannonien. Wien.

SQUARCIAPINO, M. 1942: «La decorazione frontonale in Africa e in altre provincie dell'Imperio",, Rendiconti della Pontificia Accademia, 18.

STRONG, E. 1934: «Terra Mater or Italia?» Journal of Roman Studies, 27.

STUART JONES, J. 1912: A Catalogue of the Ancient Sculptures Preserved in the Municipal Collections of Rome. The Scultures of the Museo Capitolino. Oxford.

TEPOSU MARINESCU, L. 1982: Funerary Monuments in Dacia Superior and Dacia Parolissensis. London.

TESTINI, P. 1966: Le catacombe e gli antichi cimiteri a Roma. Bologna.

VOLBACH, W. 1952: Elfenbeinarbeiten der Spätantike und der frühen Mitielalter.

WEGNER, M. 1939: Die Herrenbildnisse in antoninischer Zeit. Berlín.

- 1956: Hadrian. Berlín.

WIGGERS, H. B., y WEGNER, M. 1971: Caracalla bis Balbinus. Berlín.

WILPERT, J. 1903: Die Malereien der Katakomben Roms. Berlín.

WINKES, R. 1969: Clipeata Imago. Studien zu einer römischen Bildnisform. Bonn.

WREDE, H. 1978: «Die Austattung stadtrömischer Grabtempel und der Übergang zur Körperbestattung», Römische Mitteilungen, 85.

- 1981: Consecratio in forma deorum. Mainz.

ZANKER, P. 1975: «Grabreliefs römischer Freigelassener». Jahrbuch des Instituts, 90.

- 1983: Provinzielle Kaiserporträts. Zur Rezeption der Selbstdarstellung des Prinzeps. München. 